\title{
Correction to: Text feature extraction based on deep learning: a review
}

Hong Liang, Xiao Sun, Yunlei Sun *i] and Yuan Gao

\section{Correction to: J Wireless Com Network (2017) 2017:}

211. https://doi.org/10.1186/s13638-017-0993-1

After publication of this work [1] we became aware that we had incorrectly used the term "thesis" on three occasions. On these occasions the term "article" should have been used. We apologise to the readers for any confusion caused by this error.

Received: 7 February 2018 Accepted: 7 February 2018

Published online: 16 February 2018

\section{Reference}

1. H Liang, X Sun, Y Sun, Y Gao, Text feature extraction based on deep learning: a review. EURASIP J. Wirel. Commun. Netw. 2017, 211 (2017). https://doi.org/10.1186/s13638-017-0993-1

\footnotetext{
* Correspondence: sunyunlei@upc.edu.cn

College of Computer and Communication Engineering, China University of Petroleum (East China), No. 66, Changjiang West Road, Huangdao District, Qingdao 266580, China
} 